\title{
A Case Series of Post Covid Lung Fibrosis in Dialysis Patients; A Prospective Study
}

\author{
Unnimaya $\mathrm{K} \mathrm{L}^{1^{*}}$, Malavika $\mathrm{T} \mathrm{R}^{1}$, Sulfath $\mathrm{T} \mathrm{S}^{2^{*}}$, Ashique ${ }^{2}$ \\ 1* Pharm D Intern, Department of Pharmacy Practice, Cherraan's College of Pharmacy, Coimbatore, Tamilnadu, India. \\ 2* Clinical pharmacist, IQRAA International Hospital and Research Centre, Calicut, Kerala, India. \\ *Corresponding author's E-mail: unnimayalohi123@gmail.com
}

Received: 14-01-2021; Revised: 25-02-2021; Accepted: 04-03-2021; Published on: 20-03-2021.

\begin{abstract}
Corona virus disease is an infectious disease caused by newly discovered SARS-CoV2 (severe acute respiratory syndrome corona virus 2). Most people infected with covid 19 virus will experience mild to moderate respiratory illness and recover without requiring special treatment. Older people and those with underline medical problems like cardio vascular disease, diabetes, chronic respiratory disease and cancer are more likely to develop serious illness 1 . Even after recovery from covid 19 several patients readmitting in hospital with breathlessness, cardiac, lung and other complications. The CRP level and D-Dimer value were highly elevated for all the patients and on chest x-ray lung fibrotic changes were noted. Intravenous corticosteroid were given to the patients because of their potent anti inflammatory action that have been used in treatment of other respiratory diseases. Broad spectrum antibiotics were given to all patients as empirical therapy in order to prevent possible super imposed bacterial infection.
\end{abstract}

Keywords: Cardio Vascular risk, ESRD, Lung Fibrosis, SARS-CoV2.

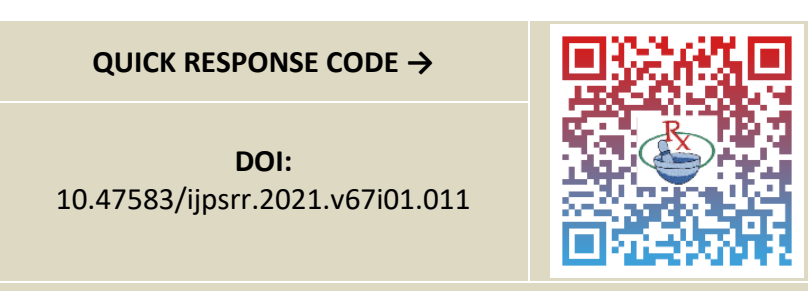

DOI link: $\underline{\text { http://dx.doi.org/10.47583/ijpsrr.2021.v67i01.011 }}$

\section{INTRODUCTION}

n Wuhan, Hubei province, China, on December 31, 2019, an outbreak of the novel corona virus nCoV-19 (SARS-CoV2), responsible for corona virus disease-19 (COVID-19), was first identified. With nearly 3 million confirmed infections and 200,000 deaths within the first four months, it has spread rapidly worldwide. Fever, muscle aches, cough, energy loss, exhaustion, breathlessness, memory issues, cognitive impairment, stress, anxiety, lung damage, heart disorders, Post Traumatic Stress Disorder (PSTD) were the most frequently identified after disease symptoms from mild, moderate to extreme. Pulmonary fibrosis is also known to result in significant and/or permanent lung damage from other causes, such as connective tissue disorders, chronic granulomatous diseases, drugs, and respiratory infections. Various mechanisms of lung injury have been identified in COVID-19, with implications for both viral and immunemediated mechanisms. Additional factors, apart from these, may predispose individuals to serious lung injury and contribute to an increased risk of survivor mortality or pulmonary fibrosis. In this research, the pathological processes involved in the production of fibrosis are addressed and the pathogenesis of lung injury in COVID-19 infection is investigated and four post-covid pulmonary pulmonary disease studies are reviewed. A clinical result of acute and chronic interstitial lung disorders is lung fibrosis. Failed alveolar re-epithelialization, persistence of fibroblasts, and excessive deposition of collagen and other components of the extracellular matrix (ECM) as well as degradation of the normal lung architecture characterise lung fibrosis. The aetiology of lung fibrosis is uncertain: the fibrotic process may lead to smoking, viral infection, drug exposure, and genetic predisposition. The key cause for lung fibrosis is chronic inflammation, which can lead to epithelial damage and activation of fibroblasts. Nevertheless, recent studies have indicated that the key causes for most lung fibrotic processes are alveolar epithelial injury and the development of active myofibroblast foci. A collection of growth factors and cytokines, including monocyte chemoattractant protein-1 (MCP-1), growth factor-b1 transforming agent (TGF-b1), tumour necrosis factor-a (TNF-a), interleukin-1b (IL-1b), and interleukin-6 (IL-6), are overexpressed and released by the cells once damage occurs in lung tissue. One of the major origins of these fibrogenic factors 2 is type II alveolar epithelial cells.

In our case series we included four End Stage Renal Disease (ESRD) patients on dialysis with post covid lung fibrosis and their management.

\section{CASE REPORTS}

Case 1: A 61 yr old male patient was admitted in Intensive Care Unit (ICU) with breathing difficulty, pain all over the chest and slurring of speech during hemodialysis who was under covid 19 treatment and tested Rapid Antigen Test (RAT) negative 1 week before. Patient is a known case of autosomal dominant polycystic kidney disease on hemodialysis with Artery Disease (CAD), Cerebro Vascular Accident (CVA). On general examination pulse was found 
to be 84 bpm, RR; 24cpm, Blood Pressure (BP); 190/70 mmhg, spo2; 84\% on room air. Further lab investigation shows Hemoglobin (hb) ;8.5gm/dl, CRP;95.10 mg/l, D.Dimer; $1101.30 \mathrm{ng} / \mathrm{ml}$. on chest x-ray shown lung fibrotic changes suggestive of possible post covid lung fibrosis.

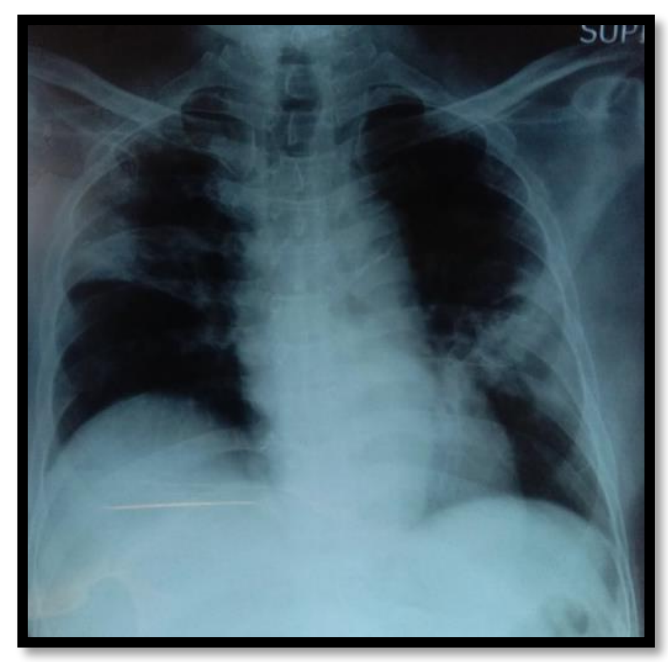

Patients HRCT lungs shows:

- Multifocal ground glass opacities and mild septal thickening in bilateral ling fields predominantly in sub Dural locations, likely infectious etiology viral pneumonia

- Volume loss in right lower lob with fibrotic changes. Sub dural linear bands in bilateral posterobasal segments

- Paraseptal emphysematous bulla in bilateral upper lobes

The patient was managed with T.Azhitromycin 500mg once daily (od), Inj. Dexamethazone $6 \mathrm{mg}$ IV twice daily (bd) given for first two days and dose changed to $8 \mathrm{mg}$ IV bd, T.Zinc 50mg p/o bd for 2 days, Inj. Cefoperazone sodium+salbactam $1 \mathrm{gm}$ iv bd, Tab. Homin D3 1tab per oral (p/o) od 4 days, INJ.Heparin 5000 IU s/c bd, Cap. Aspirin+Atorvastatin 75/10mg 0-0-1, Inj.Erythropoitin 4000iu 3 per week, T. Rabeprazole+Domperidone 30/20mg, T. Nicorandil 5mg p/o bd, T. Evabradin 2.5-0$2.5 \mathrm{mg}$, T.Vitamin C 500mg p/o od, T. Elemental zinc 50mg $\mathrm{p} / \mathrm{o}$ bd, T. Clopidogrel 75mg 0-1-0, Syp.Lactulose 30ml p/o hs for 1 day.

CASE 2: A 48yr old male patient was admitted in ICU with post covid secondary infection and diagnosed as sepsis, septic shock and fungal infection. Patient having medical history of ESRD, kidney transplant rejection on Medical Hemodialysis (MHD). On general examination HR; 120/min, RR;40cpm, spo2;84\%, BP; $110 / 40$ mmhg. Further lab investigations shows $\mathrm{Hb} ; 9.1 \mathrm{gm} / \mathrm{dl}$, WBC; 35600 $\mathrm{cu} / \mathrm{mm}$; bilirubin total; 1.21, SGPT; $330 \mathrm{IU}, \mathrm{Na} ; 134 \mathrm{mEq} / \mathrm{I}$, k;6.64 mEq/l, aPTT;42.8 , INR;1.21, CRP; 92.5 gm/l, DDimer; $598.23 \mathrm{ng} / \mathrm{ml}$. lung $\mathrm{x}$-ray suggestive of lung collapse.

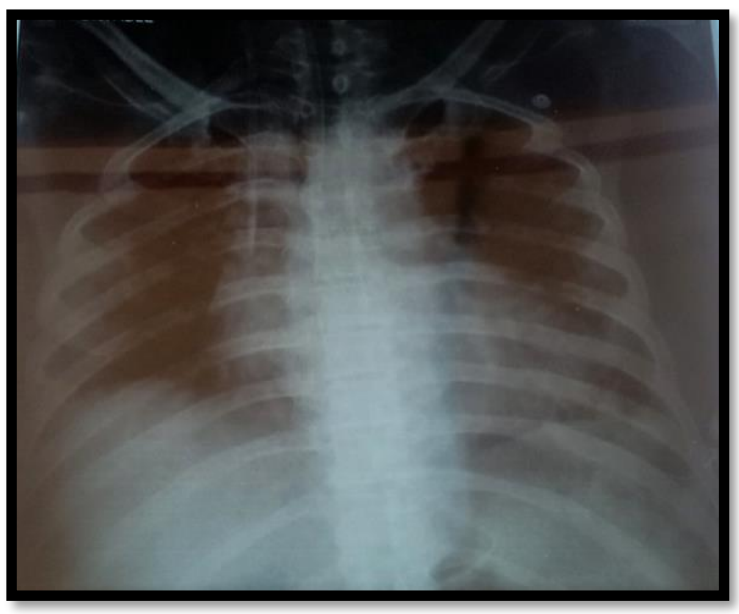

HRCT lungs shows: bilateral multifocal, peripheral and posterior predominant ground glass opacities are noted with patchy consolidation in left lung lower lob-findings are consistent with covid 19 viral infection. Total CT score is 20 (50-75\% involvement in all lobes).

The patient was managed with Inj.Heparin 5000iu s/c bd, Inj. Dexamethazone $6 \mathrm{mg}$ iv od for 5 days, Inj. Voriconazole $400 \mathrm{mg}$ iv bd and the dose changed to $200 \mathrm{mg}$ iv bd, $100 \mathrm{mg}$ iv bd, Inj. Meropenam 2g iv od, tab. Aspirin 150mg od, tab. Atorvastatin 40mg od, inj. Colestin $9 \mathrm{mu}$ iv post HD, Inj. Hydrocortisone $50 \mathrm{mg}$ iv tid for 3 days, Inj. Vancomycin $750 \mathrm{mg}$ iv post HD, Tab. Clopidogrel $75 \mathrm{mg}$ p/o od. Inj. Amphotericin iv in $250 \mathrm{ml}$ dextrose $5 \%$ over $5 \mathrm{hr}$, infusion Noradrenaline $4 \mathrm{mg}$ in NS (48ml), infusion fentanyl $200 \mathrm{mg}$ in NS $(48 \mathrm{ml})$, infusion calcium gluconate $10 \%$ iv over $10 \mathrm{~min}$, infusion sodium bicarbonate $100 \mathrm{ml}$ iv, infusion $25 \%$ dextrose+ $10 \%$ insulin $100 \mathrm{ml}$ iv, infusion magnesium sulphate $25 \% 2 \mathrm{gm}$ iv over $2 \mathrm{hr}$. Patient was expired after 7 days of post covid treatment.

CASE 3: a 67 yr old male patient was admitted to ICU with complaints of breathing difficulty and pulmonary oedema. Patient having a medical history of CAD, ESRD on MHD, DM, HTN. On general examination BP;138/50, PR; 77/min, spo2- 94\%, RR- 24cpm. Further lab investigation shows elevated WBC; 16200cells/cumm, Neutrophill; 97\%, aPTT; 84, Na; 134; K; 2.8, Hb;8.9, CRP; 89.8 gm/l, D-Dimer; 440.1 $\mathrm{ng} / \mathrm{ml}$. chest $\mathrm{X}$-ray suggestive of lung fibrosis.

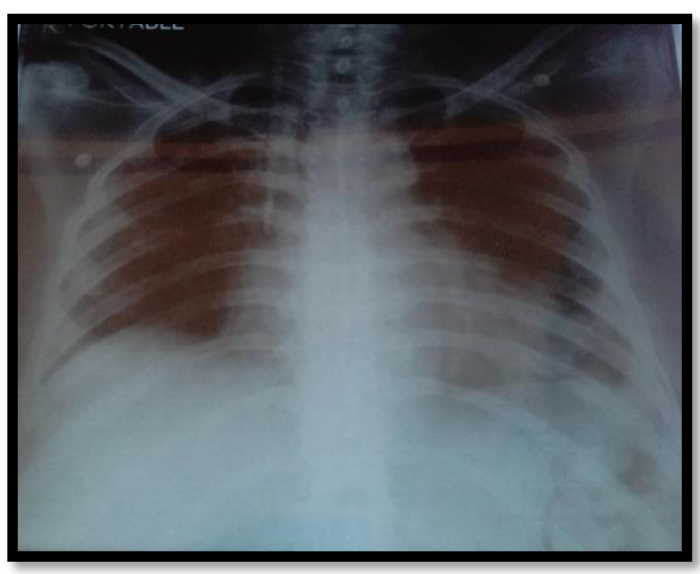


The patient was managed with Inj. Dexamethasone $6 \mathrm{mg}$ iv bd, inj. Erythropoietin 4000 iu s/c once in 5 days, inj. Heparin 5000 iu bd tab. Atorvastatin $10 \mathrm{mg}$ p/o od, tab. Aspirin 75mg p/o 0-1-0, Tab. Cilnidipine 10mg od, Inj. Cefoperazone sodium+salbactam $1 \mathrm{gm}$ iv bd, tab shelcal $500 \mathrm{mg}$ p/o bd, tab .ivabradine $2.5 \mathrm{mg}$ bd ,Tab Pantoprazole $40 \mathrm{mg}$ od.

CASE 4: A 70 yr old male patient was admitted in ICU with complaints of breathing difficulties and diagnosed as pulmonary oedema. Patient having medical history of Diabetes, Hypertension and ESRD on MHD. On general examination BP; 150/90mmhg, PR;96cpm, RR;28bpm, Temp;26 f, spO2; 90\%. Further lab investigations shows reduced $\mathrm{Hb} ; 7.9 \mathrm{gm} / \mathrm{dl}, \mathrm{Na} ; 133 \mathrm{mmol} / \mathrm{l}$, elevated WBC; 15,500 cumm, Neutrophill; 89\%, ESR; 120mm/hr CRP; 222 mg/l, D-Dimer; >10,000 ng/ml, Troponin1 HS; 250.8 pg/ml, Creatinine; $8.1 \mathrm{mg} / \mathrm{dl}, \mathrm{AST} ; 138 \mathrm{U} / \mathrm{L}, \mathrm{ALT} ; 78 \mathrm{u} / \mathrm{l}$, Alkaline phosphates;225 u/l. lung $\mathrm{x}$-ray suggestive of lung fibrosis.

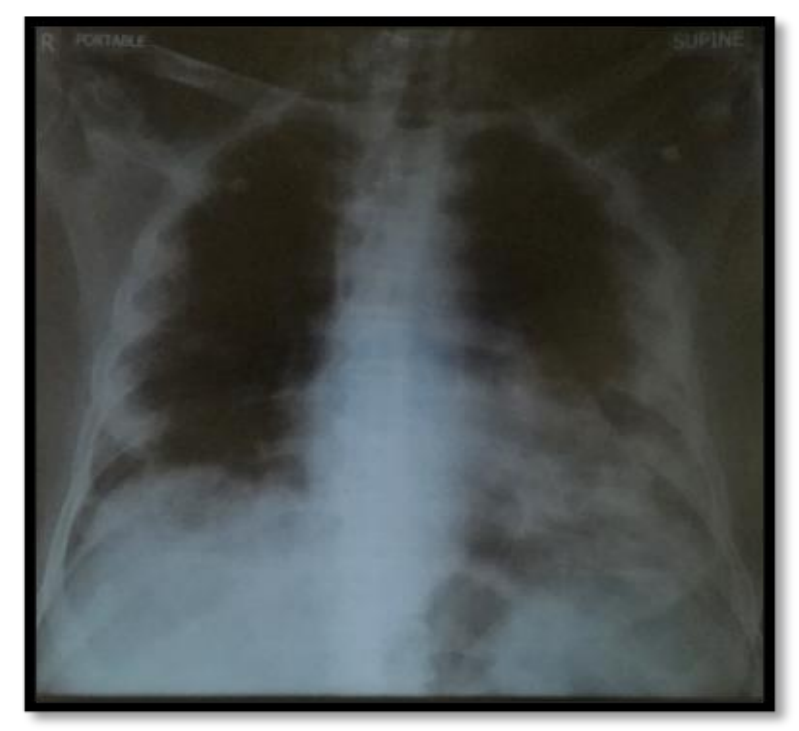

HRCT lungs show:

- Multiple large areas of ground glass opacities in both lungs in the peripheral sub pleural distributionconsistent with atypical pneumonia ( known case of covid 19) - late phase

- Subcutaneous emphysema in the lower neck and upper anterior chest wall

The patient was managed with Inj. Dexamethasone $6 \mathrm{mg}$ iv q12h for $1^{\text {st }} 7$ days, Inj. Heparin 4500iu iv q6h, Inj. Pantoprazole $40 \mathrm{mg}$ iv od for all the days, Inj. Piperacillin+ tazoctam $2.5 \mathrm{~g}$ tid, T. shelcal 500mg 1-0-1 for all the days, Neb. Ipratropium bromide q8h for all the days, Inj. Renerve plus in $100 \mathrm{ml}$ NS iv od, Inj.Ceftriaxone $2 \mathrm{~g}$ iv od given for 2 days, T. methylprednisolone $16 \mathrm{mg} 1-0-1$ for $1^{\text {st }}$ week, Inj. Erythropoietin 4000iv twice weekly, T. Gabapentin + Methylcobalamine $100 \mathrm{mg}$ 0-0-1 for all the days, T. Multivitamins od for all the days, Inj. Iron sucrose $200 \mathrm{mg}$ 2/month.

\section{DISCUSSION}

Defeating the virus could be the start of the battle for covid19 patients. For years, even after recovery, people with severe symptoms of the virus can face problems. People with kidney failure and other serious chronic medical problems are at greater risk of developing more serious illnesses.

People on dialysis can have a weakened immune system, making infections more difficult to combat. However, as advised by their health care staff, kidney patients must proceed with their regularly scheduled dialysis therapies and take the appropriate precautions ${ }^{3}$.

There is a greater risk of developing post-covid pulmonary fibrosis in people with ESRD. It also contributes to scarring of lung tissue which can reduce the quality of life of HD patients. In some cases lung fibrosis may affect the cardiac health of ESRD patients.

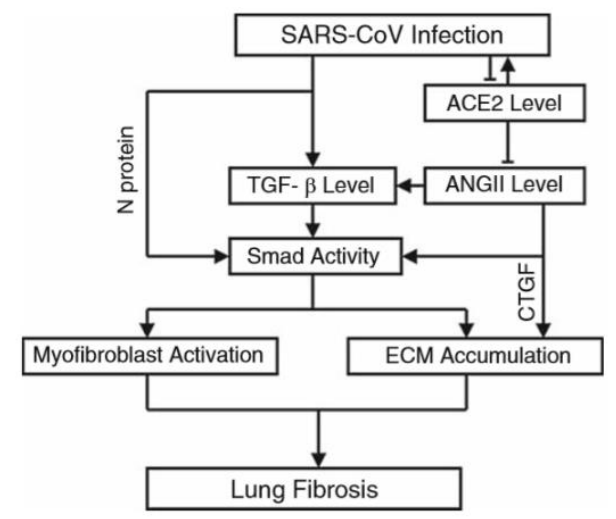

Pathological mechanisms involved in the development of Fibrosis $^{2}$

In this case series we included 4 post covid cases of ESRD patients on dialysis with lung fibrosis. From the above cases the spO2 level of the patients were reduced. CRP level was highly elevated for these patients. Recent studies show that level of CRP value was associated positively with lung lesion and seriousness of the disease. Higher levels of CRP may be a predictive marker in determining which patients with mild corona virus disease will progress to a severe case. Aspirin and Atorvastatin were given to all the patients. The fact that aspirin and statins have different biological mechanism of action but their anti inflammatory effects may contribute to the beneficial effects on CVD. . Both aspirin and statins reduce CRP level, a predictive marker of inflammation and predict the future risk of CVD ${ }^{4}$.

In all the above cases the D-Dimer value are elevated highly than the normal range. IFCC Recently published guidelines on covid 19 recommends D-Dimer testing in covid 19 patients showed a high association between incidence and outcome in patient with elevated D-Dimer level. For predicting the development of acute respiratory distress in covid 19, the increased D-Dimer value can be used. In all these 4 cases increased D-Dimer value was treated by giving inj. Heparin which was also given for DVT prophylaxis for bedridden patients ${ }^{5}$. 
In this study it is found that Inj. Dexamethzone is given for the four patients. The action of Dexamethasone in pulmonary disease is not completely known but Intravenous Dexamethasone administration will decrease morbidity and mortality of patients with lung fibrosis caused by covid 19 infections. Expected benefits of anti inflammatory therapy includes earlier liberation from mechanical ventilation, less probability of complication such as extubation failure, multi system organ failure, earlier discharge from ICU and hospital ${ }^{6}$.

Broad spectrum antibiotics were given to these patients as empirical therapy in order to prevent possible super imposed bacterial infection.

\section{CONCLUSION}

As majority of the pathways associated with covid 19 might trigger lung fibrosis and irreversible damage to lungs, making it mandatory to monitor the health status of the recovered patients. ESRD patients with covid 19 have high index of suspicion in the setting of pandemic by the exposure to health care staff and other hemodialysis patient. It is mandatory to get a comprehensive analysis of patients post-recovery states. This is very essential to understand the basic and long term effects of post covid.

\section{REFERENCES}

1. World Health Organization. Clinical management of COVID-19: interim guidance, 27 May 2020. World Health Organization; 2020.

2. Zuo W, Zhao X, Chen YG. SARS coronavirus and lung fibrosis. InMolecular Biology of the SARS-Coronavirus 2010 (pp. 247-258). Springer, Berlin, Heidelberg.

3. www.kidney.org
4. Wellens HJ. Cardiac arrhythmias: the quest for a cure: a historical perspective. Journal of the American College of Cardiology. 2004 Sep 15;44(6):1155-63.

5. Zhang L, Yan X, Fan Q, Liu H, Liu X, Liu Z, Zhang Z. Ddimer levels on admission to predict in-hospital mortality in patients with Covid-19. Journal of Thrombosis and Haemostasis. 2020 Jun;18(6):1324-9.

6. Villar, Jesus, et al. "Efficacy of Dexamethasone treatment for patientswith the acute respiratory distress syndrome caused by COVID-19: study protocol for a randomized controlled superiority trial." Trails 21.1 (2020): 1-10.

7. Lechowicz K, Drożdżal S, Machaj F, Rosik J, Szostak B, Zegan-Barańska M, Biernawska J, Dabrowski W, Rotter I, Kotfis K. COVID-19: the potential treatment of pulmonary fibrosis associated with SARS-CoV-2 infection. Journal of Clinical Medicine. 2020 Jun;9(6):1917.

8. Ojo AS, Balogun SA, Williams OT, Ojo OS. Pulmonary Fibrosis in COVID-19 Survivors: Predictive Factors and Risk Reduction Strategies. Pulmonary Medicine. 2020 Aug 10;2020.

9. Schwensen HF, Borreschmidt LK, Storgaard $M$, Redsted S, Christensen S, Madsen LB. Fatal pulmonary fibrosis: a post-COVID-19 autopsy case. Journal of Clinical Pathology. 2020 Jul 28.

10. Hong $D$, Long L, Wang AY, Lei $Y$, Tang $Y$, Zhao JW, Song X, He Y, Wen E, Zheng L, Li G. Kidney manifestations of mild, moderate and severe coronavirus disease 2019: a retrospective cohort study. Clinical Kidney Journal. 2020 May 30.

Source of Support: None declared.

Conflict of Interest: None declared.

For any question relates to this article, please reach us at: editor@globalresearchonline.net New manuscripts for publication can be submitted at: submit@globalresearchonline.net and submit_ijpsrr@rediffmail.com 